\title{
UNIDADES NATURAIS DA BACIA HIDROGRÁFICA DO RIO DOCE - RN
}

\author{
Cleanto Carlos Lima da Silva ${ }^{(a)}$, Joyce Clara Vieira Ferreira ${ }^{(b)}$, Ivaniza Sales Batista ${ }^{(\mathrm{c})}$, \\ Ermínio Fernandes ${ }^{(d)}$
}

(a) Departamento de Geografia, UFRN, cleantocarlos13@gmail.com

(b) Departamento de Geografia, UFRN, joyceclara@hotmail.com

(c) Departamento de Geografia, UFRN, ivanizas@ymail.com

(d) Departamento de Geografia, Turismo e Humanidades, UFSCAR, erminio.fernandes@gmail.com

\section{Eixo: SISTEMAS GEOMORFOLÓGICOS: ESTRUTURA, DINÂMICAS E PROCESSOS}

\begin{abstract}
RESUMO
O presente artigo tem por objetivos identificar e caracterizar as unidades naturais na bacia hidrográfica do Rio Doce. Para tanto, utilizamos como procedimentos metodológicos a compartimentação topográfica de Ab'saber (1969), a classificação taxonômica de Ross (1992) e as considerações sobre mapeamento do IBGE (1994). Os resultados da pesquisa indicaram três unidades naturais (Unidade Natural faixa litorânea; Unidade Natural Tabuleiro Costeiro; Unidade Natural Depressão Sertaneja) identificadas na bacia do Rio Doce, localizada no estado do Rio Grande do Norte, em partes dos territórios dos municípios de Ielmo Marinho, Taipu, Ceará Mirim, São Gonçalo do Amarante, Extremoz e Natal.
\end{abstract}

Palavras chaves: compartimentação do relevo, bacia hidrográfica, rio Doce, Rio Grande do Norte.

\section{Introdução}

A bacia hidrográfica do Rio Doce é considerada uma das mais importantes bacias da capital do estado do Rio Grande do Norte por abastecer uma parcela significativa da população da Região Metropolitana de Natal (RMN). Nos últimos anos, esta bacia hidrográfica vem lidando com a interferência do processo de urbanização decorrente do crescimento imobiliário da zona norte de Natal, do município de São Gonçalo do Amarante e de Extremoz com a expansão do distrito industrial. Tal crescimento acarretou em usos inadequados do solo, contribuindo para o desenvolvimento de processos erosivos em determinadas áreas no interior da bacia hidrográfica.

Nas áreas rurais da bacia do Rio Doce ocorre a presença significativa de propriedades agropecuárias de pequeno e médio porte, que por meio do manejo inadequado do solo, deixa o terreno exposto às condições de erosividade das chuvas. Essas intervenções contribuem para a aceleração dos processos erosivos que acabam influenciando o sistema pedológico e consequentemente, também, afeta as condições hídricas da bacia do Rio Doce.

Diante disso, o presente artigo tem por objetivos identificar e caracterizar as unidades naturais presentes na bacia hidrográfica do Rio Doce através da compartimentação geomorfológica. A bacia estudada abrange uma área de aproximadamente $387,8 \mathrm{~km}^{2}$ e resulta das nascentes dos rios Guajiru e 


\section{OS DESAFIOS DA GEOGRAFIA FÍSICA NA FRONTEIRA DO CONHECIMENTO Instituto de Geociências - Unicamp Campinas - SP \\ 28 de Junho à 02 de Julho de 2017}

Mudo que se interligam a Lagoa de Extremoz dando origem ao Rio Doce que deságua no estuário do Rio Potengi (Figura 01). Os municípios de Ielmo Marinho, Taipu, Ceará-Mirim, São Gonçalo do Amarante, Extremoz e Natal possui partes dos seus territórios contidos na Bacia do Rio Doce.

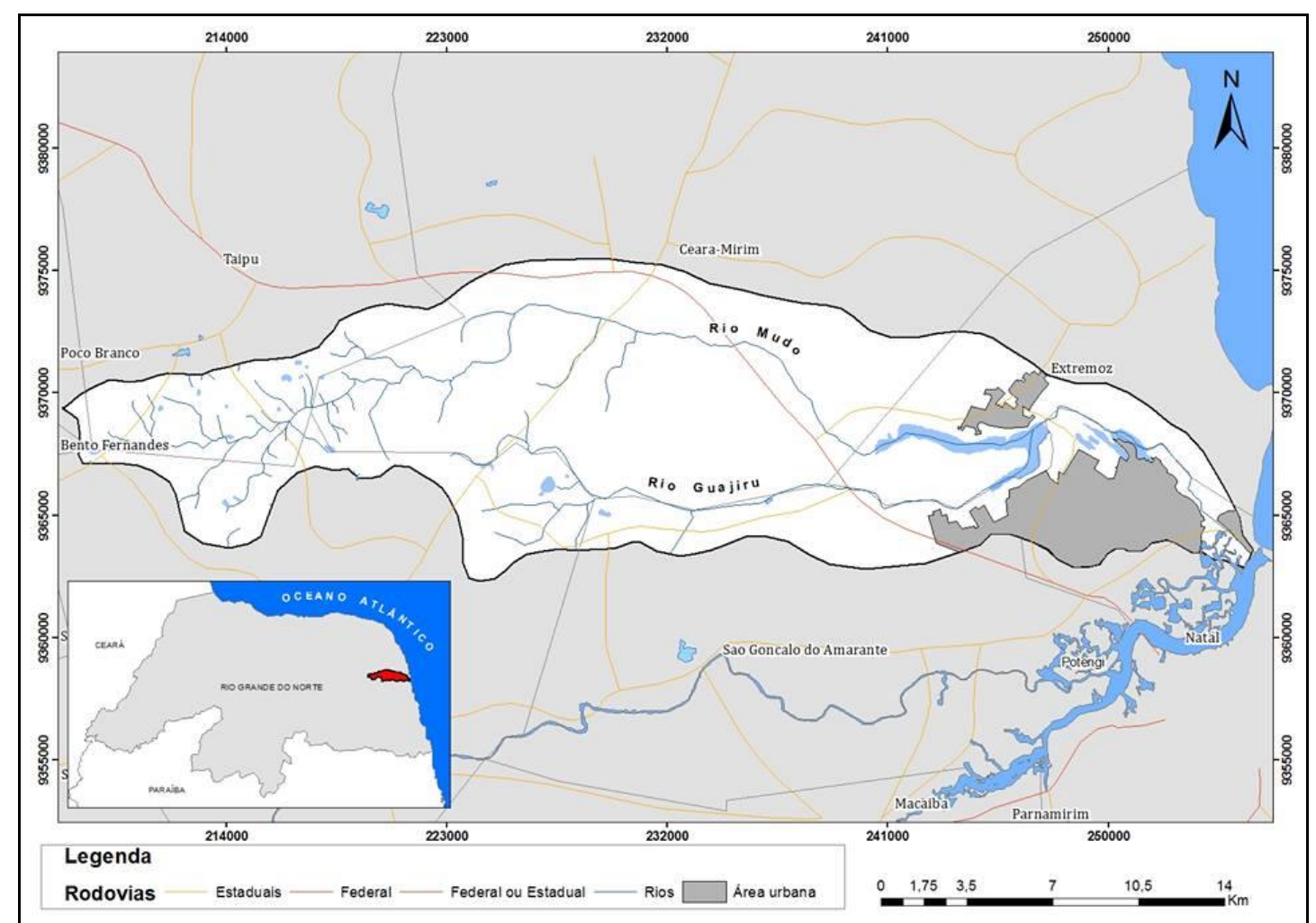

Figura 01: Localização da Bacia Hidrográfica do Rio Doce. Elaborado por Cleanto Carlos, 2016.

Assim, entende-se que a importância de compartimentar a geomorfologia da bacia hidrográfica do Rio Doce e gerar sua cartografia geomorfológica consiste em uma maneira de espacializar as formas do relevo, que se desenvolveram através de processos morfogenéticos, além de contribuir para o entendimento das dinâmicas da paisagem. Logo, cada unidade delimitada na compartimentação é considerada como um táxon detentor de uma dimensão espacial e temporal própria.

\section{Metodologia}

Como abordagem metodológica, baseou-se na compartimentação geomorfológica de Ab'Sáber (1969), que atenta para os processos de formação do relevo no espaço e no tempo. Corroborando nesta perspectiva, fizemos uso dos níveis de escala de detalhe referente a proposta taxonômica de Ross (1992). Este autor, apresenta seis níveis taxonômicos objetivando a análise das formas de relevo e a análise estrutural superficial da paisagem, embasados na proposta metodológica de Ab'Saber (1969). A taxonomia foi delimitada da seguinte forma: unidades morfoestruturais ( $1^{\circ}$ táxon), unidades 
OS DESAFIOS DA GEOGRAFIA FÍSICA NA FRONTEIRA DO CONHECIMENTO

Instituto de Geociências - Unicamp

Campinas - SP

28 de Junho à 02 de Julho de 2017

morfoesculturais ( $2^{\circ}$ táxon), padrões fisionômicos de formas ( $3^{\circ}$ táxon), formas de relevo ( $4^{\circ}$ táxon), elementos em formas de vertentes ( $5^{\circ}$ táxon) e formas de processos atuais ( $6^{\circ}$ táxon) (ROSS, 1994).

Para a realização deste artigo, consideramos os táxons de $3^{\circ} \mathrm{e} 4^{\circ}$ ordem, aqui denominados, respectivamente, de Unidades Naturais e Subunidades Naturais, considerando uma escala de detalhe de 1:50.000. Utilizamos a terminologia "unidades naturais" por entendermos essas áreas como sistemas integrados e por compreendermos o relevo como um fator importante para a compartimentação das unidades físicas que formam a bacia hidrográfica. Destarte, ressalta-se que o delimitador da bacia e de seus subsistemas, está intimamente ligado com seu substrato geológico e sua composição pedológica.

\section{Resultados: Unidades Naturais da Bacia Hidrográfica do Rio Doce}

O mapeamento geomorfológico tem como função a ordenação hierárquica dos fatos geomorfológicos, para que se possa representá-los de uma forma que agrupe os sucessivos conjuntos de modelados de relevo em unidades geomorfológicas (ROSS, 1992). A espacialização das unidades de relevo permite o reconhecimento dos elementos do meio físico e constituí-se como um relevante subsídio para o planejamento, gestão do uso e ocupação territorial em bacias hidrográficas, ao considerá-las como unidades integradas da paisagem (Unidades Naturais) em sua totalidade dinâmica e complexa.

Na realização do mapeamento das unidades naturais da bacia hidrográfica do rio Doce, utilizamos os dados Shuttle Radar Topography Mission - SRTM para as primeiras análises morfológicas. Dentre as cartas elaboradas com base no MDT (Modelo Digital de Terreno), as de maior importância foram a hipsométrica e a de declividade das vertentes, revelando, assim, as primeiras áreas homogêneas para a classificação topográfica. Também foram levados em consideração para o mapeamento do relevo os bancos de dados disponibilizados pelo IDEMA (2005) e pela CPRM (2006), os quais deram suporte para a elaboração dos mapas temáticos de geologia, geomorfologia e pedologia referentes à área em questão.

Na carta de declividade das vertentes observou-se a conformação de relevo plana em quase toda a extensão da bacia, coincidindo com a classificação geomorfológica de tabuleiros costeiros da Formação Barreiras. Já nas porções territoriais de maior declividade sobressaem-se as vertentes dos rios Mudo e Guajiru, apresentando áreas com declives superiores a $45^{\circ}$, o que também coincide com os principais focos de erosão mapeados na bacia. Assim, as classes de declividade foram divididas com base na Embrapa (1979), considerando o relevo como: plano (0\% a 3\%), suave-ondulado (3\% a $8 \%$ ), ondulado ( $8 \%$ a $20 \%$ ), forte-ondulado (20\% a $45 \%)$, montanhoso (45\% a $75 \%$ ) e fortemontanhoso (maior que 75\%).

A análise hipsométrica apresentou um aumento da altitude de leste para oeste, variando de 1 metro até 140 metros acima do nível do mar. Na parte leste observamos as Planícies litorâneas, na porção central 
XVII Simpósio Brasileiro

de Geografia Física Aplicada

I Congresso Nacional

de Geografia Física

\section{OS DESAFIOS DA GEOGRAFIA FÍSICA NA FRONTEIRA DO CONHECIMENTO Instituto de Geociências - Unicamp \\ Campinas - SP \\ 28 de Junho à 02 de Julho de 2017}

foi identificado o Tabuleiro Costeiro e, finalmente, na parte oeste da bacia o relevo é característico da Depressão Sertaneja.

Após a integração desses dados, foram realizadas análises mais minuciosas com a finalidade de detalhar as formas de relevo visando a compartimentação das unidades naturais. Para tanto, utilizamos das análises das fotografias aéreas, somadas a interpretação visual das imagens das imagens de satélites disponibilizadas pelo Google Earth - Pró e a análise dos mapas temáticos elaborados previamente (geologia, geomorfologia e pedologia). Sendo primordial, a realização da pesquisa de campo para a correção e validação dos resultados encontrados.

Conforme o mapeamento, foram distinguidas o total de três unidades geomorfológicas, as quais denominamos de Faixa Litorânea (porção leste da bacia), Tabuleiro Costeiro (porção central da bacia) e da Depressão Sertaneja (porção Oeste da bacia). A primeira unidade é composta por três subunidades; a segunda unidade é constituída por quatro subunidades; e a terceira, constituída por duas subunidades (Quadro 01 e Figura 02).

Com base na metodologia de Ross (1992), as subunidades geomorfológicas são identificadas por letras e símbolos, conforme suas naturezas genéticas, desse modo, a letra "A" representa as formas "Agradacionais" (de acumulação) e a letra "D" indica as formas "Denudacionais" (de erosão). As formas de acumulação (A) são acompanhadas de duas outras letras que são indicativas da gênese e do processo da forma de acumulação, enquanto as formas denudacionais (D) são acompanhadas de letras minúsculas que se referem à morfologia do topo das formas de denudação, podendo ser classificadas em: tabular (t), planar (p), convexa (c) e aguçada (a).

Nesse sentido, na próxima seção, serão caracterizados os aspectos naturais contidos em cada unidade e subunidade geomorfológicas. É importante destacar que compreendemos o relevo como fator importante para a delimitação das unidades físicas da bacia hidrográfica, estando associado com as formações geológicas e sendo fator delimitador dos tipos de solos que, por sua vez, também influenciam no tipo de vegetação e na rede hidrografica. Por fim, ressaltamos que as subunidades geomorfológicas, identificadas na bacia hidrográfica do rio Doce, corresponderam às unidades geológicas da área, conforme os dados fornecidos pela CPRM (2006).

Quadro I - Unidades Naturais, subunidades e suas características. 


\begin{tabular}{|c|c|c|c|c|c|c|}
\hline $\begin{array}{l}\text { Unidades } \\
\text { Naturais }\end{array}$ & $\begin{array}{c}\text { Aspectos Gerais da } \\
\text { Unidade }\end{array}$ & $\begin{array}{c}\text { Subunidades } \\
\text { Naturais }\end{array}$ & $\begin{array}{c}\text { Características } \\
\text { Geológicas }\end{array}$ & $\begin{array}{l}\text { Características } \\
\text { Geomorfológicas }\end{array}$ & $\begin{array}{c}\text { Características } \\
\text { Pedológicas }\end{array}$ & Vegetação \\
\hline $\begin{array}{c}\text { Faixa } \\
\text { Litorânea }\end{array}$ & $\begin{array}{l}\text { Área predominantemente } \\
\text { aplainada, variando a } \\
\text { altitude em tomo de } 10 \text { a } \\
50 \text { metros, tendo como } \\
\text { base geológica os } \\
\text { sedimentos do período } \\
\text { quartenáno, como as } \\
\text { dunas, paleodumas e } \\
\text { aluviões. Apresentando } \\
\text { como principal forma de } \\
\text { relevo e as planícies e as } \\
\text { dunas associadas às } \\
\text { depressõesinterdunares. }\end{array}$ & \begin{tabular}{|l|} 
1.Planície \\
fluviomarinha \\
(Apfm). \\
2.Duna (Ade). \\
3.Planície \\
fluviolacustre \\
(Apfl).
\end{tabular} & $\begin{array}{|lr|}\text { Depósitos r } & \text { de } \\
\text { mangues } & \text { com } \\
\text { sedimentos } & \\
\text { inconsolidados. } \\
\text { Depósitos élicos } \\
\text { litorâneos r de } \\
\text { dunas r } \\
\text { paleodunas. } \\
\text { Depósitos } \\
\text { eluvionares, } \\
\text { formados por } \\
\text { cascalho, areia e } \\
\text { argila. }\end{array}$ & \begin{tabular}{llr|} 
Superficie & plana \\
resultante de processos \\
de & acumulação & fluvial \\
e marinha. & \\
Comporta & as & dunas \\
fixas e as dunas móveis \\
e & as & depressões \\
interdunares. & \\
Área & plana & resultante \\
da & combinação & de \\
processos & & de \\
acumulação & fluvial & e \\
lacustre. & &
\end{tabular} & $\begin{array}{l}\text { Solos Gley, } \\
\text { hidromórfico e } \\
\text { tiomórfico. } \\
\text { Neossolos } \\
\text { quartzarênicos. } \\
\text { Solos aluviais. }\end{array}$ & $\begin{array}{c}\text { Vegetação } \\
\text { de } \\
\text { manguezal. } \\
\text { Vegetação } \\
\text { de restinga }\end{array}$ \\
\hline $\begin{array}{l}\text { Tabuleiro } \\
\text { Costeiro }\end{array}$ & 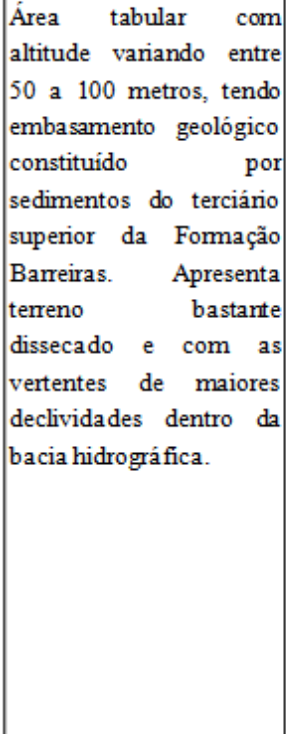 & $\begin{array}{l}\text { 1.Denudacion } \\
\text { al homogênea } \\
\text { Plana (Dp). } \\
\text { 2.Denudacion } \\
\text { al homogênea } \\
\text { convexa (Dc). } \\
\text { 3.Denudacion } \\
\text { al homogênea } \\
\text { Tabular(Dt). } \\
\text { 4.Planície de } \\
\text { inundação } \\
\text { (Ai). }\end{array}$ & \begin{tabular}{|l|} 
Depósitos \\
colúvio- \\
eluvionais sobre a \\
Formação \\
Barreiras. \\
Depósitos \\
colúvio- \\
eluvionais sobre a \\
Formação \\
Barreiras. \\
Depósitos \\
aluviais \\
Formação \\
Barreira. \\
Material coluvial \\
recentes, formado \\
por silte e areia.
\end{tabular} & 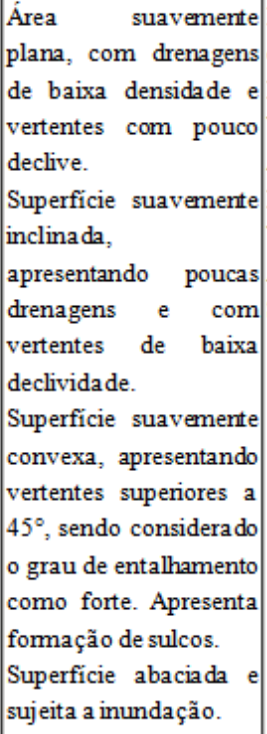 & $\begin{array}{l}\text { Bruno } \\
\text { cálcico. } \\
\text { Latossolo } \\
\text { Vermelho } \\
\text { Amarelo. } \\
\text { Latossolo } \\
\text { Vermelho } \\
\text { Amarelo. } \\
\text { Solos Aluviais. } \\
\\
\end{array}$ & $\begin{array}{c}\text { Vegetação } \\
\text { de } \\
\text { tabuleiro }\end{array}$ \\
\hline $\begin{array}{l}\text { Depressão } \\
\text { Sertaneja }\end{array}$ & 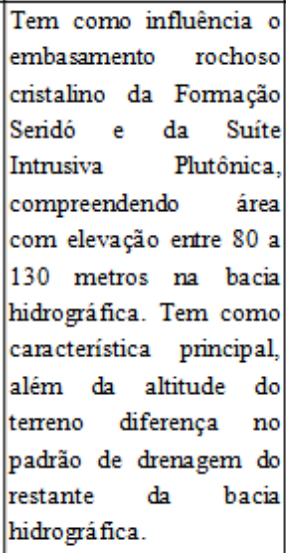 & $\begin{array}{l}\text { 1.Denundacio } \\
\text { nal Estrutural } \\
\text { Convexo } \\
(\mathrm{DEa}) . \\
\text { 2.Denundacio } \\
\text { nal Estrutural } \\
\text { Planar(DEp). }\end{array}$ & 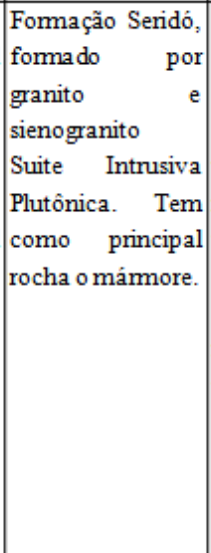 & 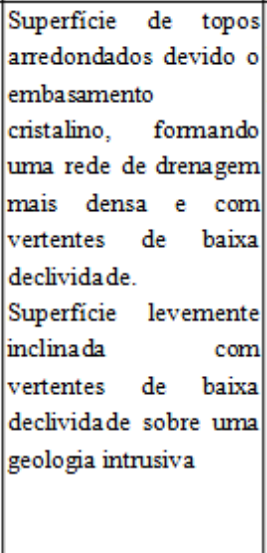 & $\begin{array}{l}\text { Podzólico } \\
\text { Vermelho } \\
\text { Amarelo } \\
\text { equivalente } \\
\text { Eutrófico. } \\
\text { Planossolo. } \\
\end{array}$ & $\begin{array}{l}\text { Vegetação } \\
\text { de caatinga }\end{array}$ \\
\hline
\end{tabular}




$$
\text { Campinas - SP }
$$

28 de Junho à 02 de Julho de 2017

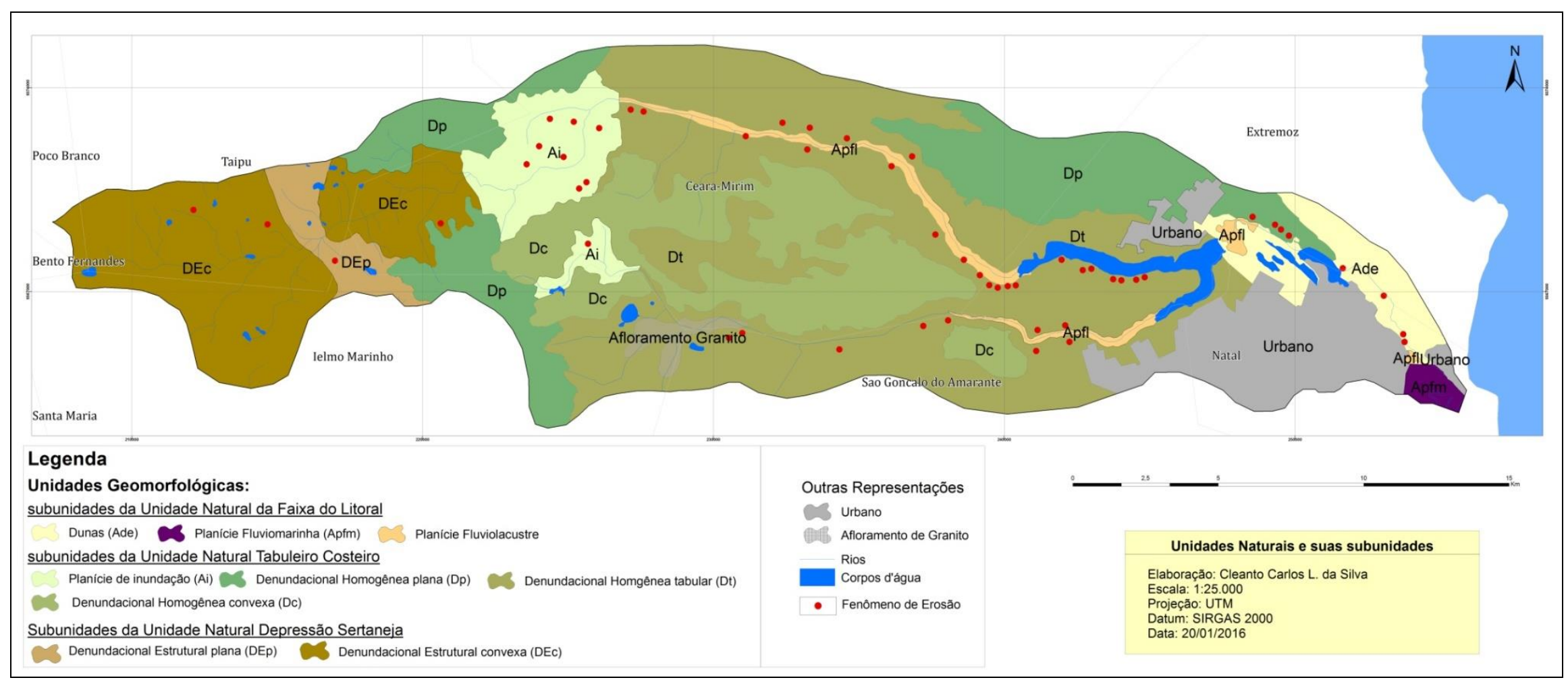

Figura 02 - Bacia Hidrográfica do Rio Doce: Unidades Naturais 
XVII Simpósio Brasileiro

de Geografia Fisica Aplicada

I Congresso Nacional

de Geografia Física
OS DESAFIOS DA GEOGRAFIA FÍSICA NA FRONTEIRA DO CONHECIMENTO

Instituto de Geociências - Unicamp

Campinas - SP

28 de Junho à 02 de Julho de 2017

\subsection{Unidade Natural Faixa Litorânea}

Chamamos de Faixa Litorânea a unidade natural da porção leste da bacia hidrográfica do rio Doce, pois a área apresenta características físicas que recebem influências marítimas, devido a presença de dunas e manguezal, compreendidas como subunidades "Ade" e "Apfm", respectivamente. Além dessas duas subunidades, há uma terceira, que compreende a Planície Flúvio Lacustre - "Apfl”.

Como definição pelo IBGE (1995), estas três subunidades se classificam geomorfologicamente, como: Duna (Ade) - Depósitos eólicos formados em função do estoque de sedimentos fornecidos pelo sistema fluvial ou costeiros pelo regime de ventos. Elas ocorrem principalmente nas regiões litorâneas, onde o regime do vento é favorável; Planície Fluviomarinha (Apfm) - área resultante de processos de combinações de acumulação fluvial e marinha, ocorrendo nas baixadas litorâneas, próximo às embocaduras fluviais; Planícies Fluviolacustres (Apfl) - áreas planas resultantes dos processos fluviais e lacustres, conformadas em áreas que recebem influência dos efeitos de acumulação combinada dos rios e lagos, sujeitos a inundações periódicas.

A Faixa Litorânea é formada por subunidades constituídas de sedimentos do período Quaternário (Neógeno) dispostos sob o Grupo Barreira de idade Terciária (Paleógeno), sendo consideradas como formas de acumulação. Os sedimentos de idade quaternária constituem as dunas e paleodunas, depósitos de mangues e aluviões presentes na área de estudo.

Quanto ao clima, de acordo com a classificação de Köppen, a predominância é do tipo As - clima tropical chuvoso quente com verão seco. De acordo com os dados do Instituto Nacional de Meteorologia (INMET), considerando as normais climatológicas de 1961 a 1990, a temperatura média anual da área é de $26^{\circ} \mathrm{C}$ com precipitação em torno de $1400 \mathrm{~mm}$ distribuídas anualmente de janeiro a julho. A maior concentração de focos erosivos ocorre nesta unidade, em detrimento das demais, podendo estar associada à elevada taxa pluviométrica, às características dos seus solos (essencialmente arenosos e fisicamente inconsolidados) e a pressão exercida pela ocupação urbana local.

Ademais, como se trata de uma unidade de formação geológica e geomorfológica mais recente, sua pedologia é pouco evoluída, ou seja, os processos pedogenéticos são incipientes, refletindo na configuração de solos do tipo neossolos e indiscriminados de mangue. Constituindo o grupo dos Neossolos desta unidade, temos os Neossolos Quartzarênicos da subunidade "Ade", caracterizado por ser bastante arenoso e apresentar somente os horizontes A e C, portanto, classificado como pouco evoluído (EMBRAPA, 2006); temos também os Neossolos Flúvicos, caracterizado por depósitos de sedimentos aluviais que apresentam sobreposição de camadas sedimentares sem relações pedogenéticas entre elas. (EMBRAPA, 2006).

Os solos indiscriminados de mangue, encontrados na subunidade "Apfm", apresentam características de material pouco desenvolvido, escuros, lamacentos, com alto teor de sais proveniente de água do mar e composto de enxofre (EMBRAPA, 2006). A presença do mangue na área é considerada como 
XVII Simpósio Brasileiro

de Geografia Física Aplicada

I Congresso Nacional

de Geografia Física
OS DESAFIOS DA GEOGRAFIA FÍSICA NA FRONTEIRA DO CONHECIMENTO

Instituto de Geociências - Unicamp

Campinas - SP

28 de Junho à 02 de Julho de 2017

um indicador da salinidade do solo (OLIVEIRA, 2011). Ressalta-se que com a vigência da adequação do Sistema Brasileiro de Classificação dos Solos (SiBCS), no ano de 2006, esses solos passaram a ser denominados de gleissolos tomórficos.

No que se refere à cobertura vegetal, vale salientar que esta é fortemente condicionada pelas características dos solos que as sustentam. Os solos de natureza arenosa dão suporte à vegetação do tipo restinga, podendo ser mais densa, com porte arbustivo-arbóreo situado nas encostas e topos das dunas (Ade) e uma vegetação herbácea, psamófila, menos densa, nas áreas mais úmidas (SOARES, 2006).

Na subunidade natural "Apfm", que compreende a área de mangue, a vegetação é considerada do tipo manguezal, desenvolvida em solos tiomórficos (abundância de enxofre) e hidromórficos, sendo caracterizada como uma vegetação que recebe influencia dos sistemas fluvial e marinho. Por fim, na subunidade "Apfl" se destaca a formação de vegetação hidrófila, herbácea, associada às lagoas e áreas úmidas (ROCHA, 2015).

\subsection{Unidade Natural Tabuleiro Costeiro}

A unidade natural de Tabuleiro Costeiro é considerada de maior extensão espacial, localizada no médio curso da bacia do rio Doce, destaca-se, principalmente, por seu relevo tabular formado sobre a Formação Barreiras. Como subunidades naturais, destacamos: Plano de inundação (Ai), compreendendo a área mais nova de toda unidade natural, sendo a única unidade deposicional; Denundacional homogênea plana (Dp); Denundacional homogênea tabular (Dt) e Denundacional homogênea convexa $(\mathrm{Dc})$.

De acordo com a classificação geomorfológica do IBGE (1995), estas quatro subunidades são distinguidas da seguinte maneira: Planície de inundação (Ai) - área abaciada resultante de planos convergentes, sujeito a inundação periódicas, incorporadas a rede de drenagem; Denundacional homogênea plana (Dp) - área suavemente plana, com drenagens de baixa densidade e vertentes com pouco declive; Denundacional homogênea tabular (Dt) - considerada a maior subunidade natural da bacia do rio Doce, apresentando terreno em forma de "mesa", apresentando as maiores inclinações das vertentes próximas aos dois principais rios da bacia - Rio Mudo e Guajiru. É também considerada como a subunidade com maior desgaste; Denundacional homogênea convexa (Dc) - área suavemente ondulada, com topos arredondados e vales bem definidos.

De acordo com os dados da CPRM (2007), a unidade natural do Tabuleiro Costeiro, geologicamente, apresenta Depósitos colúvio-eluviais (N23c), Grupo Barreiras (ENb), e o afloramento Suíte Intrusiva Dona Inês (NP3 $\gamma 2$ di). As subunidades naturais têm suas delimitações coincidindo com esses limites geológicos. Os Depósitos colúvio-eluviais (N23c) são característicos das subunidades de Denundacional plana (Dp) e Denundacional convexa (Dc), sendo definidos como sedimentos arenosos 
OS DESAFIOS DA GEOGRAFIA FÍSICA NA FRONTEIRA DO CONHECIMENTO Instituto de Geociências - Unicamp Campinas - SP

28 de Junho à 02 de Julho de 2017

e areno-argilosos esbranquiçados, por vezes, constituído de depósitos conglomeráticos com seixos de quartzo predominante.

O Grupo Barreiras (ENb) compreende as subunidades Plano de inundação (Ai) e Denundacional tabular (Dt). Esta formação geológica já foi descrita na Unidade Natural Litorânea. Já a Suíte Intrusiva Dona Inês (NP3 $\gamma 2$ di) se encontra aflorando dentro da subunidade Denundacional tabular (Dt). Esta formação se trata de rochas plutônicas, sendo composta de sienogranitos equigranulares de granulação fina a média (CPRM, 2007). Vale destacar que a área de afloramento é usada por pedreiras na exploração de rochas ornamentais.

O clima dessa unidade natural não se diferencia do clima tratado na unidade anterior, sendo caracterizado como um clima tropical chuvoso quente com verão seco - As, com temperaturas variando entre $21^{\circ} \mathrm{C}$ e $31^{\circ} \mathrm{C}$ (CASTRO, 2000; SOARES, 2006). Os meses entre março e junho são considerados como o período de excedente hídrico e no restante do ano ocorre déficit hídrico, de acordo com os dados de INMET da estação de Ceará-Mirim, 1961 -1990.

A cobertura pedológica que se encontram nessa unidade, conforme a base de dados do IDEMA (2005), é demarcada por solos do tipo Latossolos Amarelos Distróficos. De acordo com Oliveira (2011), os latossolos apresentam avançado estágio de intemperismo e material coloidal com baixa capacidade de troca catiônica, além da ausência de minerais primários. Estas características são condições que hes conferem a distrofia, ou seja, a baixa fertilidade.

A vegetação predominante desta unidade natural é do tipo estépica arborizada (vegetação de tabuleiro), formada por dois estratos: um arbóreo-arbustivo e um herbáceo, sendo ralo e descontínuo, com exceção da subunidade natural Plano de inundação (Ai), que apresenta vegetação de área alagada, ocorrendo a presença da carnaúba associada, frequentemente, aos solos alagadiços, de várzeas ou em margens de rios no Nordeste brasileiro.

\subsection{Unidade Natural Depressão Sertaneja}

A unidade natural da Depressão Sertaneja localiza-se no alto curso da bacia Hidrográfica do Rio Doce, onde estão situadas as principais nascentes do rio Mudo. Nesta Unidade, o rio Mudo passa a obter drenagem do tipo dendrítica, apresentando apenas duas subunidades naturais: Denundacional Estrutural convexo (DEc) e Denundacional Estrutural plano (DEp).

De acordo com a classificação geomorfológica do IBGE (1995), estas subunidades são caracterizadas da seguinte forma: Denundacional Estrutural convexo (DEc) - área de vertentes com declividades variadas, entalhadas por sulcos e cabeceiras de drenagens de primeira ordem. Denundacional homogênea plana (DEp) - definida por rede de drenagem de baixa densidade, com vertentes de pequenas declividades. 
OS DESAFIOS DA GEOGRAFIA FÍSICA NA FRONTEIRA DO CONHECIMENTO Instituto de Geociências - Unicamp Campinas - SP

28 de Junho à 02 de Julho de 2017

O clima da unidade se diferencia das outras duas, pois, embora seja classificada como clima As tropical chuvoso com verão seco, também recebe influência do clima semiárido, registrando temperatura média anual de $25,3{ }^{\circ} \mathrm{C}$, com precipitação anual média em torno dos $750 \mathrm{~mm}$ (CPRM, 2005). Essa pluviosidade diferenciada do restante da bacia, juntamente com a geologia, corroboram na conformação de aspectos únicos, tornando a unidade natural Depressão Sertaneja a mais divergente da bacia.

Na Unidade Natural da Depressão Sertaneja encontramos como seu delimitador a geologia, constituída por um embasamento cristalino de natureza ígnea e metamórfica, sendo considerada como um dos elementos mais influenciadores da área, por condicionar uma rede de drenagem diferenciada, refletindo em um maior número de ramificações.

Como unidades geológicas temos a Formação Seridó (NP3ss), embasando a subunidade Denundacional Estrutural plana (DEp), e Suíte Intrusiva Dona Inês (NP3 2 2di), que integra a subunidade natural Denundacional Estrutural convexa (DEc). A primeira se trata de uma formação geológica metamórfica formada no período Ediacariano da Era Neoproterozóica. Sua litologia dominante consta de micaxistos feldspáticos (ANGELIM et al. 2006). Já a Suíte Intrusiva Dona Inês (NP3 $\gamma 2$ di), como dito anteriormente, é composta de rochas plutônicas, sendo constituída de sienogranitos equigranulares de granulação fina a média (CPRM, 2007), também do período Ediacariano.

Nessa unidade, devido à escala de pouco detalhe, observa-se unicamente a classe dos Latossolos Amarelos Distróficos (IDEMA, 2005). Em trabalho de campo, o solo apresentou-se com coloração esbranquiçada, arenoso e bem drenado. Esses Latossolos podem ser definidos como solos maduros, bem intemperizados, com ausência de minerais primários e baixa capacidade de troca catiônica.

Quanto à vegetação predominante, localmente, observa-se a savana estépica arbustiva (caatinga hipoxerófila), caracterizada pela presença de arbustos e árvores com espinhos, adaptadas a ambientes secos. Isso, em consonância com as características de clima mais seco, com pluviosidade média anual bem menor que as outras unidades.

Portanto, diante do apresentado, entendemos que após a identificação e caracterização das três unidades e subunidades naturais que compõem a bacia hidrográfica do Rio Doce, observamos que há uma distinção entre elas e, que apesar disso, seus aspectos e elementos contidos no sistema hidrográfico conseguem manter relações e influência mútuas que contribuem na configuração paisagística atual da bacia em estudo.

\section{Considerações finais}


O conhecimento das unidades que formam a bacia hidrográfica do Rio Doce, juntamente com a concepção das mesmas enquanto subsistemas que formam o sistema maior que é a bacia, possibilita um melhor aproveitamento dos recursos naturais, como também, propicia bases para criação de modelos de gestão a partir da análise de bacias hidrográficas, focando no desenvolvimento sustentável e integrado dos municípios compõem a bacia. Nesse sentido, após a identificação das três unidades e subunidades naturais, que compõem a bacia hidrográfica do Rio Doce, observamos que ambas são bastante distintas, porém seus aspectos físicos mantêm relações e influência mútuas.

Vale salientar também que a compreensão dos aspectos físicos como componentes de cada unidade da bacia do Rio Doce, possibilita novos estudos para a área, sendo base para pesquisas sobre a pedologia, o uso e ocupação do solo e erosão, além de estudos com ênfase na questão hidrográfica, tendo em vista a importância dos recursos hídricos da bacia para o abastecimento da porção norte da região metropolitana de Natal, Rio Grande do Norte.

\section{Bibliografia}

AB'SABER A.N. Um conceito de geomorfologia a serviço das pesquisas sobre o quaternário. Geomorfologia, n.18, 1969c.

BRASIL, Serviço Geológico do Brasil - CPRM. Projeto cadastro de fontes de abastecimento por água subterrânea. Diagnóstico do município de Bento Fernandes, estado do Rio Grande do Norte. Recife: CPRM/PRODEEM, 2005a.

BRASIL, Serviço Geológico do Brasil - CPRM. Projeto Cadastro de Fontes de Abastecimento Por Água Subterrânea: Diagnóstico do Município de Jandaira/RN. Recife-PE: CPRM/PRODEM, 2005b.

BRASIL, Instituto Brasileiro de Geografia e Estatística - IBGE. Manual Téenico de Geomorfologia. $1^{\circ}$ edição. Rio de Janeiro, 1995.

ROSS, J. L. S. O Registro Cartográfico dos Fatos Geomorfológicos e a Questão Taxonômica do Relevo. Revista do Departamento de Geografia - USP. EDUSP Editora. N 6, Pg: 17 - 30. 1992.

ROSS, J. L. S. Suporte da Geomorfologia Aplicada: os táxons e a cartografia do relevo. Departamento de Geografia da Universidade Federal de São Paulo - USP. São Paulo, 1994. www.geomorfologia/forum.com.br . Acesso 30/03/2010.

\section{Agradecimentos}

Os autores agradecem a Universidade Federal do Rio Grande do Norte (UFRN), ao Departamento do curso de Geografia (DGE) e a Coordenação de Aperfeiçoamento de Pessoal de Nível Superior (CAPES) pelo incentivo financeiro. 